\title{
A Combination of Water-Steam Distillation and Solvent Extraction of Cananga Odorata Essential Oil
}

\author{
Megawati ${ }^{1 *}$, and Saputra, S. W. D \\ ${ }^{1,2}$ Chemical Engineering, Faculty of Engineering, Semarang State University, Bldg E1, \\ Sekaran, Gunungpati, Semarang 50229, Indonesia
}

\begin{abstract}
Cananga odorata is an agricultural product with potential to produce essential oil because of its high volatile components content. In this study, the essential oil production of Cananga odorata from Indonesia was investigated using a combination of water-steam distillation and solvent extraction. Depending on extracted oil during distillation, the mass transfer modelling as a main extraction parameter to the design calculation was described. Meanwhile, in the solvent extraction, influence of difference solvent of oxygenated compound group of the produced oil was studied in order to increase in the oil quality. From the experiment results, the cananga oil yield of the water-steam distillation is about $0.936 \% \mathrm{v} / \mathrm{w}$ of fresh flower and the oil contains several components like trans-carryopyllene $(39.03 \% \mathrm{w} / \mathrm{w})$, alpha humulene $(11.59 \% \mathrm{w} / \mathrm{w})$, alpha bergamotene $(11.29 \% \mathrm{w} / \mathrm{w})$, and germacrene (10.94\%). It is observed that the oil mass transfer occurs in two regimes i.e. constant mass transfer and decreasing mass transfer regimes. It is found that the oil mass transfer of watersteam distillation is about $2.52 \times 10^{-6}$ mole/g.min.mmHg. In addition, the solvent extraction of the oil produced by the water-steam distillation can increase the oxygenated compounds, from $15.86 \%$ increase to 25.3 and $25.34 \%$ for chloroform and diethyl ether solvents, respectively.
\end{abstract}

Keyword: Cananga odorata, essential oil, water-steam distillation, solvent extraction, mass transfer coefficient

\section{INTRODUCTION}

Cananga odorata, commonly known as Kenanga (Indonesia), ylang-ylang (Philippine), canang odorant (French); lanalana (Hawai‘i); makosoi, mokohoi, makasui, mokosoi (Fiji); moto‘i (Society Islands); moto‘oi, mata'oi, mato'oi (Tahiti); and cananga (English), is a medium-size tree at about 10-20 $\mathrm{m}$ in height that has been introduced for perfumes. This species can be found growing in forests, agro-forests, and garden. Its flowers blossom throughout the year in auxiliary, umbellate hanging clusters of 4-12 flowers, each with three and six petals up to $8 \mathrm{~cm}$ long. The young petals are twisted and are very fragrant with greenish yellow colour. Then they limp when reaches maturity which are less fragrant and deep yellow in colour. The fragrant flower can be extracted to produce the essential oil. The cananga essential oil can be used as an alternative source in the perfume industry and aromatherapy, flavouring agent in candles, icings, frozen dairy, pudding, baked goods, soft drinks and chewing gums, and food additive. As aromatherapy, the essential oil is useful for treatment of depression, distressed breathing, high blood pressure, anxiety, as an aphrodisiac, etc. Accordingly, cananga essential oil has been approved as food additives by US Food and Drugs Administration (FDA) and has been considered for food uses by Flavor and Extract Manufacturers Association (FEMA) and the International Organization of Flavor Industries (IOFIs). On other hand, in Java culture, the flower is used against malaria and to treat asthma.

In the literatures, cananga essential oil can be extracted using pressing/cold expressing [1], water distillation, water-steam distillation, steam distillation, effleurage, solvent extraction, supercritical fluid extraction, vacuum microwave hydro-distillation, and solvent-free microwave hydro-distillation methods [2]. Furthermore, there are many chemical compounds in the cananga essential oil, such as heavy oxygenated compound (benzyl benzoate); light oxygenated compound (eugenol, benzene acetate); oxygenated monoterpene (geranyl acetate, geraniol, linalool); sesquiterpen hydrocarbon (germacrene, trans-caryophyllene, pmethylanisole, camphene, anethol); nitrogenated compound (phenylacetonitrile, 4-methylbenzaldoxime, indole, methyl anthranilate) [2], [3]-[7]. Due to practicality, water-steam distillation method is opted more than other ones. In water-steam distillation, the mass transfer of the cananga essential oil is main parameters to determine the kinetics parameter of the extraction process in order to design the industrial scale equipment. In water-steam distillation, the mass balance equation can be expressed by.

$$
\begin{gathered}
\left(\begin{array}{c}
\text { the oil amount } \\
\text { of flower at time } t
\end{array}\right)=\left(\begin{array}{c}
\text { the oil amount } \\
\text { of flower at } t=0
\end{array}\right)-\left(\begin{array}{c}
\text { the oil amount } \\
\text { that has been produced } \\
\text { at time } t
\end{array}\right) \\
\qquad \begin{array}{c}
x\left(W_{\text {flower }}-W_{\text {oil }}\right)=W_{\text {flower }} x_{\text {oil }}-W_{\text {oil }} \\
x=\frac{W_{\text {flower }} x_{\text {oil }}-W_{\text {oil }}}{W_{\text {flower }}-W_{\text {oil }}}
\end{array}
\end{gathered}
$$


where: $\mathrm{x}$ is the essential oil content in flower during extraction.

In addition, the mass transfer of essential oil from flower surface occurs in two regimes i.e. constant mass transfer and decreasing mass transfer regimes. The mass transfer of essential oil is assumed constant when the essential oil yield does not yet reach a critical point. The essential oil yield in this step is higher than the critical yield and the mass transfer area in the flower surface is still constant. Whereas, when the essential oil content reached the critical yield, so the mass transfer of essential oil starts to decrease. A lot of researches that studied the mass transfer and kinetics of essential oil distillation as an important research component, such as a steam distillation for Pimpinella anisum essential oil [8], a steam distillation for Cymbopogon winterianus essential oil [9], a hydro/steam distillation for Ylang-ylang oil [10], and a steam distillation for Ocimum Basillicum [11]. In addition, the results of this model can be compared with the other models.

While, the extracted cananga essential oil by distillation method can produce not only volatile compound (essential oils) but also non-volatile compound (resin, wax, pigment, gums, fatty acids and other anhydrous oils) [2], [5]. Consequently, it is potential to purify of the cananga essential oil in order to increase the volatile compounds, especially the oxygenated compound group as the odoriferous components. The solvent extraction is one of chemically methods expect distillation and adsorption that can be applied to separate the impurities of cananga essential oil [2]. The distillation method to purify the essential oil produced by distillation must be operated at high pressure due to the boiling point of the essential oil components is high. However, the adsorption method must be conducted in very complex procedures in order to achieve the high efficiency of molecular sieve of the various oil components. Interestingly, in the present study, the essential oil purification that be conducted is solvent extraction method. In addition, the chosen solvent solutions are chloroform (a nonpolar organic solvent) and diethyl ether (a non-polar organic solvent that slightly polar). This chosen has a prediction that the essential oils are complex mixtures of a great number of different components that can be divided in the functional groups like acid, alcohol, ketone, aldehyde, esther, ether, and alkane. These functional groups have different polarity that can be written from the most to less of the polar rank as follows: acid > alcohol > ketone > aldehyde > esther > ether > alkane. Thus, the influence of solvent polarity of solvent extraction can be studied. For that previously reasons, the aims of this research are to model and find the mass transfer coefficient of the Cananga odorata essential oil extraction using water-steam distillation and to study the influence of organic solvent solution of the solvent extraction in order to increase the volatile components of the essential oil.

\section{Experiment And Method}

\section{A. The theoretically essential oil content analysis of Cananga odorata essential oil}

The Cananga odorata flower was sliced and weighted at $5 \mathrm{~g}$, and then it was extracted via soxchlet aparatus with n-hexane solvent at temperature of $70-80{ }^{\circ} \mathrm{C}$ until 20 of cycles. The attained cananga oil was distillated to evaporate the solvent at temperature of $70{ }^{\circ} \mathrm{C}$ until the oil solution volume of about $5 \mathrm{~mL}$. After that, the essential oil was dried in oven to evaporate the residual solvent. The theoretically essential oil yield is a ratio number between essential oil with fresh flower weight.

\section{B. The water-steam distillation of Cananga odorata essential oil}

$300 \mathrm{~g}$ Cananga odorata flower is extracted in $7 \mathrm{~L}$ pressure vessel operated at pressure of $1.5 \mathrm{~atm}$ (Fig. 1). The pressure vessel is equipped with a condenser, pressure gauge (in the range of 0-10 atm), 1/4" pressure relieved valve, safety valve, basket, and glass level indicator. The condensed vapour flow through in $50 \mathrm{~mL}$ beuret in order to measure the volume of the essential oil and water every time interval of $30 \mathrm{~min}$. During the process, the pressure distillation is kept constant at 1.5 bar. The pressure distillation was operated above the atmospheric condition in order to increase the extraction temperature, so that the essential oil yield can be increased. The extraction was stopped after the distillation time reach 8 hours. The essential oil density measurement was conducted using a liquid pycnometer. And then, the essential oil constituents were analysed by a Hewlett Packard HP5890 series II plus gas chromatograph equipped with a HPMS 5989b mass spectrometer using electron impact. The mass spectrometry (MS) conditions were as follows: ionization voltage, $70 \mathrm{eV}$; emission current, $40 \mathrm{~mA}$; scan rate, $1 \mathrm{scan} / \mathrm{s}$; mass range, $35-300 \mathrm{Da}$; ion source temperature, $200{ }^{\circ} \mathrm{C}$. The MS fragmentation pattern was checked with those of other essential oils of known composition, with pure compounds and by matching the MS fragmentation patterns with WILEY229 mass spectra libraries and with those in the literature. The relative amounts of the individual components were obtained from GC analysis based on peak areas using the generalized equation of Van den Dool and Kratz [12]. 


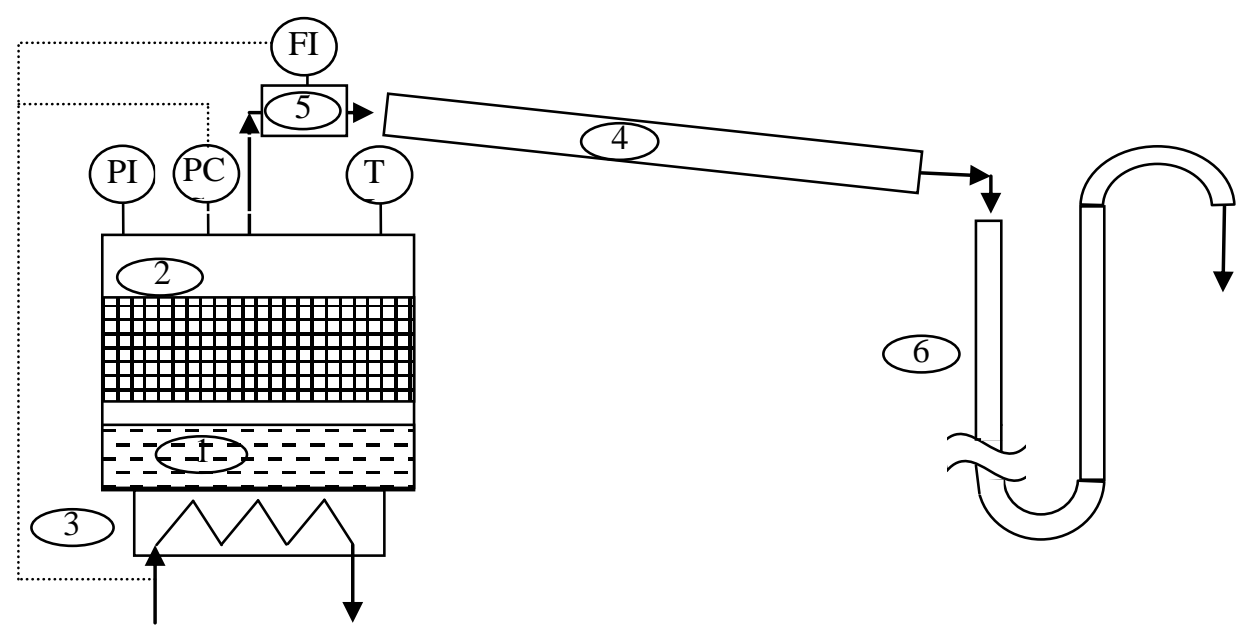

Fig. 1. Equipment schema of water-steam distillation (1: water area, 2: simplisia area, 3: heater, 4: condenser, 5: vapour valve, 6 : beuret)

\section{The solvent extraction of Cananga Odorata essential oil}

Initially, the mixture of $50 \mathrm{~mL}$ of cananga essential oil and $50 \mathrm{~mL}$ of solvent and $1 \% \mathrm{w} / \mathrm{v}$ of sodium chloride was placed in the three neck extraction flask equipped with a magnetic stirrer and condenser to prevent the solvent to come out due to the solution high volatility. Sodium chloride was added to facilitate the emulsion breakdown. The extraction is stopped when the reaction time has reached 1 hour. The variable of the research is extraction solvent i.e. chloroform (SIGMA 3045) and diethyl ether (SIGMA 3098). Before the solvent was evaporated to its recovery from the mixture with essential oil, sodium sulphate was added to remove the organic phase followed by filtration. The evaporation was conducted under a vacuum in a rotary-evaporator (SIGM 1209) at temperature of $30{ }^{\circ} \mathrm{C}$ for 4 hours. The produced cananga essential oil was stored in dark bottles at $4{ }^{\circ} \mathrm{C}$ prior to composition analysis using GC-MS method.

\section{RESULT AND DISCUSSION}

From the experiment of essential oil content using a standard procedure [1], the theoretically essential oil yield is about 1.159 and $1.324 \%$ w/w of the fresh flower for experiments 1 and 2, respectively. From the water-steam distillation, the obtained essential oil yield was about $0.936 \% \mathrm{w} / \mathrm{w}$ of the fresh flower and the density of one was about $0.9026 \mathrm{~g} / \mathrm{mL}$. It is obvious that water-steam distillation at pressure of $1.5 \mathrm{bar}$ is an efficient process that can extract the Cananga essential oil with the theoretically yield of about 71 to $81 \%$. The oil and water volumes in distillate can be seen in Table 1 and the oil mole at various times is plotted in Fig. 2. The numbers of mole and mass were then calculated by the assumption of the water density $=1 \mathrm{~g} / \mathrm{mL}$ (pure water), the water molecular weight $=18 \mathrm{~g} / \mathrm{mole}$, the oil density $=0.9026 \mathrm{~g} / \mathrm{mL}$ (constant during the process), and the oil molecular weight $=164 \mathrm{~g} / \mathrm{mole}$. The calculation results of mole and mass of the oil and water in distillate are listed in Table 1.

Table 1: Water and oil in the distillate

\begin{tabular}{|c|c|c|c|c|c|c|c|c|c|c|c|c|c|}
\hline \multirow{2}{*}{$\begin{array}{l}\text { time } \\
(\mathrm{min}) \\
\end{array}$} & \multicolumn{3}{|c|}{ water } & \multicolumn{3}{|c|}{ essential oil } & \multirow{2}{*}{$\begin{array}{l}\text { time } \\
(\min )\end{array}$} & \multicolumn{3}{|c|}{ water } & \multicolumn{3}{|c|}{ Essential oil } \\
\hline & $\mathrm{mL}$ & $\mathrm{g}$ & mole & $\mathrm{mL}$ & $\mathrm{G}$ & mole & & $\mathrm{mL}$ & $\mathrm{g}$ & mole & $\mathrm{mL}$ & $\mathrm{g}$ & Mole \\
\hline 0 & 0 & 0 & 0 & 0 & 0 & 0 & 165 & 1017 & 1017 & 165 & 1.80 & 1.6247 & 0.0099 \\
\hline 15 & 42 & 42 & 15 & 0 & 0 & 0 & 180 & 1197 & 1197 & 180 & 1.90 & 1.7149 & 0.0105 \\
\hline 30 & 72 & 72 & 30 & 0.30 & 0.2708 & 0.0017 & 195 & 1392 & 1392 & 195 & 1.95 & 1.7601 & 0.0107 \\
\hline 45 & 117 & 117 & 45 & 0.40 & 0.3610 & 0.0022 & 210 & 1602 & 1602 & 210 & 2.00 & 1.8052 & 0.0110 \\
\hline 60 & 177 & 177 & 60 & 0.50 & 0.4513 & 0.0028 & 225 & 1827 & 1827 & 225 & 2.05 & 1.8503 & 0.0113 \\
\hline 75 & 252 & 252 & 75 & 0.70 & 0.6318 & 0.0039 & 240 & 2067 & 2067 & 240 & 2.10 & 1.8955 & 0.0116 \\
\hline 90 & 342 & 342 & 90 & 0.90 & 0.8123 & 0.0050 & 255 & 2322 & 2322 & 255 & 2.15 & 1.9406 & 0.0118 \\
\hline 105 & 447 & 447 & 105 & 1.10 & 0.9929 & 0.0061 & 270 & 2592 & 2592 & 270 & 2.20 & 1.9857 & 0.0121 \\
\hline 120 & 567 & 567 & 120 & 1.30 & 1.1734 & 0.0072 & 285 & 2877 & 2877 & 285 & 2.25 & 2.0309 & 0.0124 \\
\hline 135 & 702 & 702 & 135 & 1.50 & 1.3539 & 0.0083 & 300 & 3177 & 3177 & 300 & 2.30 & 2.0760 & 0.0127 \\
\hline 150 & 852 & 852 & 150 & 1.70 & 1.5344 & 0.0094 & & & & & & & \\
\hline 165 & 1017 & 1017 & 165 & 1.80 & 1.6247 & 0.0099 & & & & & & & \\
\hline
\end{tabular}




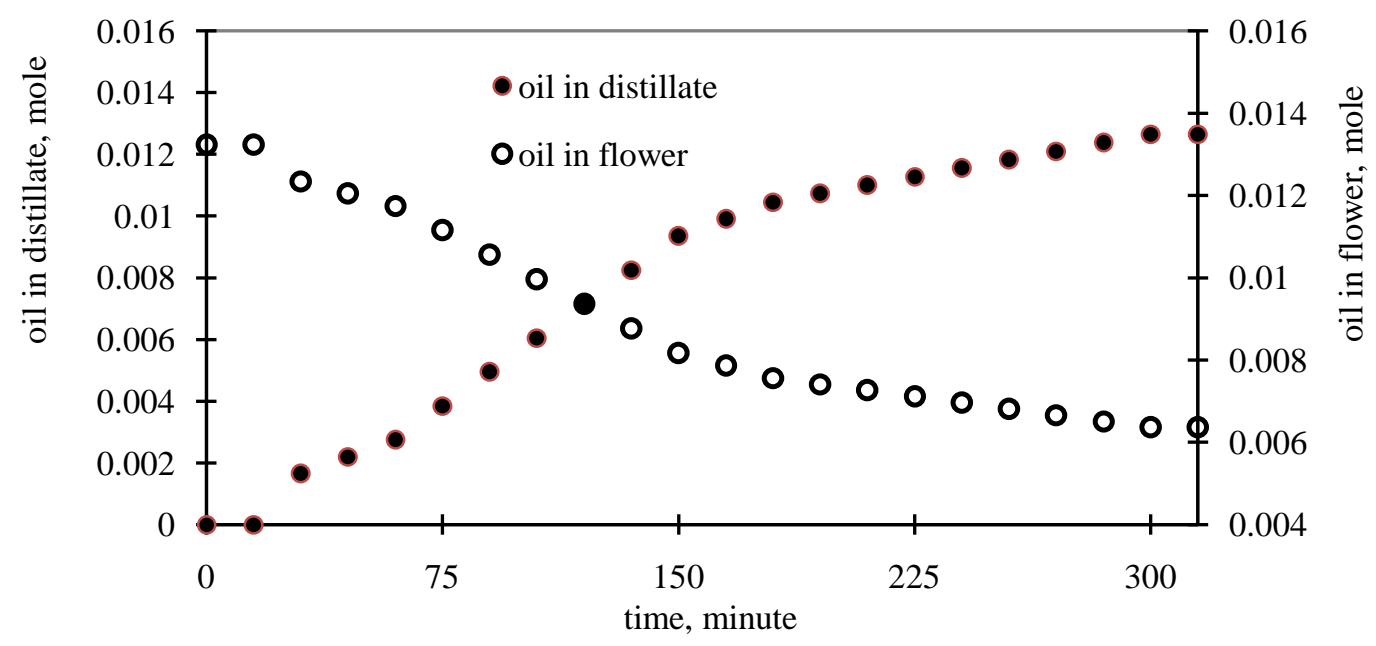

Fig. 2. Essential oil in distillate and flower

In Fig. 2, it is obvious that the correlation of the oil fraction mole between times has two phenomena. The first phenomenon is increasing of the oil mole during distillation from 0-105 minutes can be expressed by a linear curve. And the second is increasing of the oil mole starts to decrease (above 105 minutes). Accordingly, the point that increasing of oil mole starts to decrease is as a critical point of the extraction [13], [14]. The phenomena are caused by the mass transfer of essential oil from flower surface in water-steam distillation which occurs in two steps as follows.

\section{The mass transfer of essential oil is constant}

The process assumption can be applied until when the essential oil content reach a critical point. The essential oil yield in this step is higher than the critical yield and the mass transfer area in the flower surface is still constant. The essential oil yield in the flower can be calculated by Equation (3). The calculation results can be seen in Table 2 and Fig. 2.

Table 2: Essential oil fraction in flower

\begin{tabular}{|c|c|c|c|c|c|}
\hline $\begin{array}{c}\text { time } \\
(\mathrm{min})\end{array}$ & $\begin{array}{c}\text { oil fraction in flower } \\
(\mathrm{x})\end{array}$ & $\begin{array}{c}\text { Time } \\
(\mathrm{min})\end{array}$ & $\begin{array}{c}\text { oil fraction in flower } \\
(\mathrm{x})\end{array}$ & $\begin{array}{c}\text { time } \\
(\mathrm{min})\end{array}$ & $\begin{array}{c}\text { oil fraction in flower } \\
(\mathrm{x})\end{array}$ \\
\hline 0 & 0.013240 & 120 & 0.009365 & 225 & 0.007116 \\
\hline 15 & 0.013240 & 135 & 0.008767 & 240 & 0.006966 \\
\hline 30 & 0.012349 & 150 & 0.008167 & 255 & 0.006815 \\
\hline 45 & 0.012051 & 165 & 0.007867 & 270 & 0.006665 \\
\hline 60 & 0.011753 & 180 & 0.007567 & 285 & 0.006515 \\
\hline 75 & 0.011157 & 195 & 0.007417 & 300 & 0.006364 \\
\hline 90 & 0.010561 & 210 & 0.007266 & 315 & 0.006364 \\
\hline 105 & 0.009963 & & & & \\
\cline { 1 - 4 } & & &
\end{tabular}

From Table 2, the critical yield of the oil extraction attained at the time of 105 minutes and the essential oil yield in the distillate of 0.00939. This step occurs fast, consequently water and vapour are equilibrium and immiscible, so that the relation equations of pressure and water vapour fraction can be written as follows:

$$
y_{\text {water }}=\frac{P_{\text {water }}^{o}}{P}
$$

However, a relation equation of pressure and essential oil vapour fraction is as in Equation 5.

$$
y_{o i l}=\frac{P_{o i l}^{o}}{P}
$$

At the vapour phase, the water and essential oil fraction relation is

$$
y_{\text {water }}+y_{\text {oil }}=1
$$

Therefore the essential oil vapour fraction can be expressed into mole fraction in form

Rearranging above equations gives Equation (8).

$$
y_{\text {oil }}=\frac{m_{\text {oil }}}{m_{\text {oil }}+m_{\text {water }}}
$$




$$
m_{\text {oil }}=\frac{y_{\text {oil }}}{1-y_{\text {oil }}} m_{\text {water }}
$$

Equation (8) show that the relation between essential oil mole with water mole in distillate in step 1 is a linear curve with slope of $\mathrm{y}_{\mathrm{oil}} /\left(1-\mathrm{y}_{\mathrm{oil}}\right)$. From the experiment data we can make a plot of oil mole $\left(\mathrm{m}_{\mathrm{oil}}\right)$ versus water mole $\left(\mathrm{m}_{\text {water }}\right)$, so that the value of essential oil fraction in vapour can be calculated. Consequently, with Equation (6) we can evaluate the essential oil pure vapour pressure. The results of the curve linear regression of oil mole versus water mole of the Cananga odorata essential oil distillation when the process time duration is 105 minutes can be seen in Fig 3 . The slope obtained is about $2.6 \times 10^{-6}$, so that the oil fraction and pure pressure in the vapour $\left(\mathrm{y}_{\text {oil }}\right)$ are about 0.00026 and $0.152 \mathrm{mmHg}$, respectively.

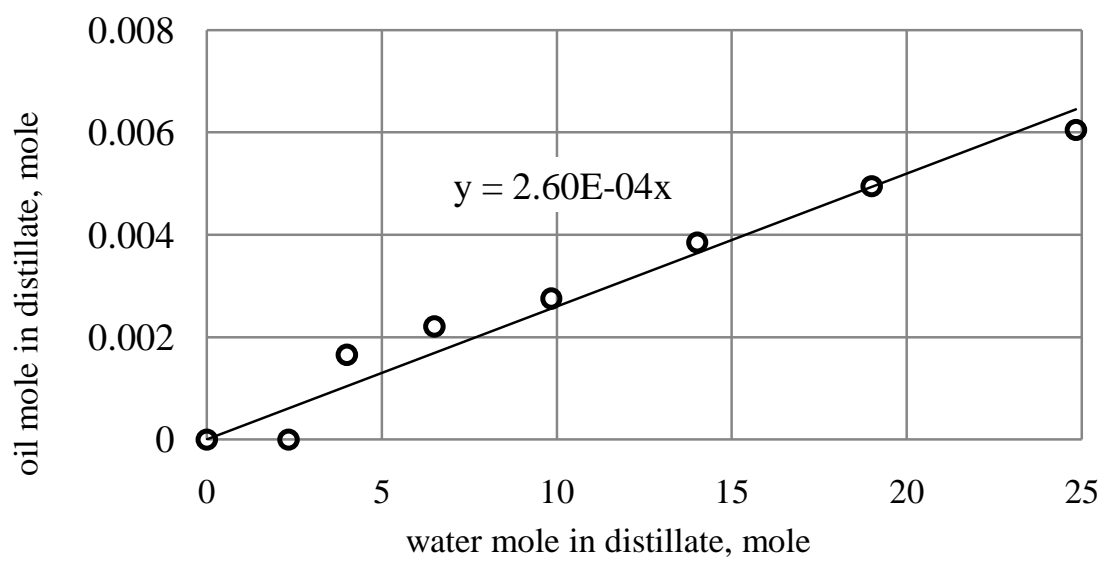

Fig. 3 Linear regression result between oil mole versus water mole in distillate

\section{The mass transfer of essential oil decreases}

The process can be applied if essential oil content reaches the critical yield and continue to decrease. In this step, the essential oil yield as well as the mass transfer area in the flower surface decrease. The mass transfer rate between phases from liquid phase to vapour phase can be arranged by Equation (9) and can be numerically solved by forming of Equation (10).

$$
\begin{aligned}
& \beta . K_{y} a=\frac{\left(\frac{d m_{\text {oil }}}{d t}\right)}{m_{\text {flower }} \cdot\left[P_{\text {oil }}^{o}-\left(\frac{d m_{\text {oil }}}{d m_{\text {oil }}+d m_{\text {water }}}\right) \cdot P_{T}\right]} \\
& \beta . K_{y} a=\frac{\left(\frac{\Delta m_{\text {oil }}}{\Delta t}\right)}{m_{\text {flower }} \cdot\left[P_{m}^{o}-\left(\frac{\Delta m_{\text {oil }}}{\Delta m_{\text {oil }}+\Delta m_{\text {water }}}\right) \cdot P_{T}\right]}
\end{aligned}
$$

If $\frac{\left(\frac{\Delta m_{\text {oil }}}{\Delta t}\right)}{m_{\text {flower }} \cdot\left[P_{\text {oil }}^{o}-\left(\frac{\Delta m_{\text {oil }}}{\Delta m_{\text {oil }}+\Delta m_{\text {water }}}\right) \cdot P_{T}\right]}=\mathrm{Z}$, so equation (10) becomes:

$$
Z=\beta . K_{y} a
$$

The value of $\beta$ can be assumed by Equation (12) and then substituted in Equation (11). The result is Equation (13).

$$
\begin{gathered}
\beta=e^{-\alpha\left(x-x_{c}\right)} \\
Z=e^{-\alpha\left(x-x_{c}\right)} \cdot K_{y} a
\end{gathered}
$$

Equation (13) can be solved by the logarithm procedure as follows:

$$
\ln (Z)=-\alpha \cdot\left(x-x_{c}\right)+\ln \left(K_{y} a\right)
$$

Parameters $\alpha$ and $K_{y} a$ can be found by linear regression of $-\left(x-x_{c}\right)$ versus $\ln (Z)$ which the values of $\alpha$ and $K_{y}$ a are values of slope and intercept of the line. Finally, from the data of oil and water moles in distillate, the mass transfer coefficient of Cananga odorata essential oil of water-steam distillation is about 2.52 x $10^{-6}$ mole/g.min.mmHg.

\section{The GC-MS analysis results of the Cananga odorata essential oil}

The GC-MS analysis results of the Cananga odorata essential oil extracted by water-steam distillation and solvent extraction can be seen in Fig. 4 and Tables 3. The composition can be accordingly divided by the oxygenated compound as in Table 4.

In Fig. 4 and Table 3, It can be seen that the main composition of Cananga odorata essential oil produced by water-steam distillation were trans-carryopyllene $(39.03 \% \mathrm{w} / \mathrm{w})$ followed alpha humulene $(11.59 \%$ $\mathrm{w} / \mathrm{w})$, alpha bergamotene $(11.29 \% \mathrm{w} / \mathrm{w})$, and germacrene $(10.94 \%)$. However, after the essential oil extracted by chloroform, the main composition were trans carryopyllene $(26.10 \% \mathrm{w} / \mathrm{w})$ followed by germacrene $(12.04 \%)$, 
and alpha humulene $(10.79 \% \mathrm{w} / \mathrm{w})$. After the essential oil extracted by diethyl ether, the main compositions were trans carryopyllene $(25.01 \% \mathrm{w} / \mathrm{w})$ followed germacrene $(10.31 \%)$, and alpha humulene $(10.86 \% \mathrm{w} / \mathrm{w})$. At the crude oil, oil extracted by chloroform, and oil extracted by diethyl ether, the compound group of the essential oils were mainly the same. The most abundant group is sesquiterpen. Other compound groups with high amount are oxygenated monoterpen, high oxygenated, and heavy oxygenated compounds. The oxygenated compound is highly odoriferous, while the sesquiterpene hydrocarbon contributes only little to fragrance produced. The quality of cananga oil increases with the content of oxygenated compounds which is the result of this purification with the solvent extraction by chloroform. The oil extracted by chloroform and diethylether contain much more oxygenated compound than the crude oil (25.3 and $25.34 \%$ versus $15.86 \%$ ). On the other hand, the sesquiterpen hydrocarbon is present in a higher quantity in the crude oil than the oil extracted by chloroform and diethylether (84.13\% versus 76.09 and $75.33 \%$ ). Therefore the purification of Cananga odorata oil by solvent extraction using chloroform yields better than the crude oil produced by water-steam distillation.
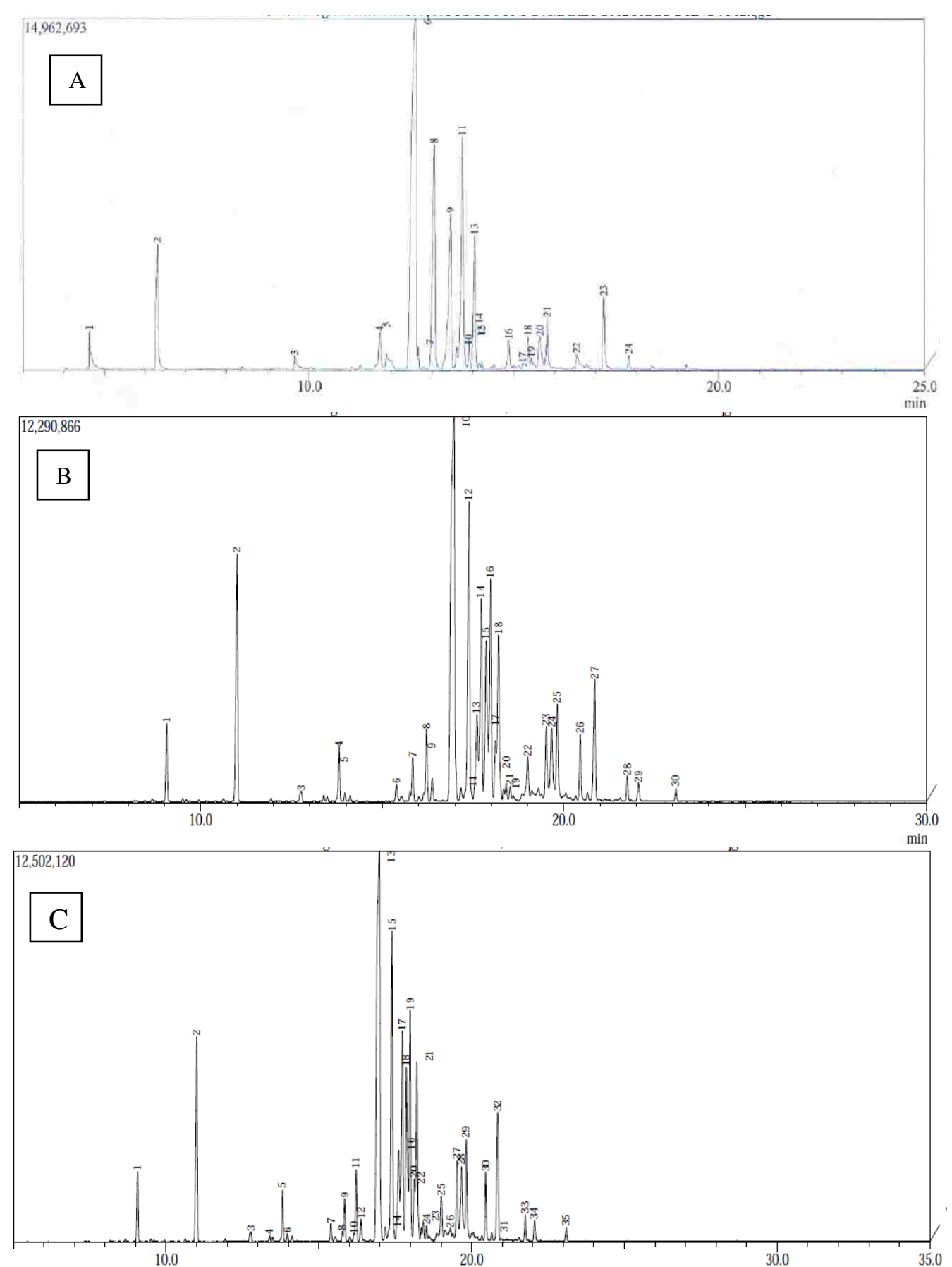

Fig. 4 Gas chromatography of A: Cananga odorata oil crude; B: Cananga odorata oil extracted by chloroform; C: Cananga odorata oil extracted by diethyl ether 
Table 3. Chemical composition (mass \%) of Cananga odorata crude oil; Cananga odorata oil extracted by chloroform; and Cananga odorata oil extracted by diethyl ether

\begin{tabular}{|c|c|c|c|c|c|}
\hline No & Composition & Type & Crude oil & $\begin{array}{l}\text { Oil extracted } \\
\text { by chloroform }\end{array}$ & $\begin{array}{c}\text { Oil extracted } \\
\text { by diethyl ether }\end{array}$ \\
\hline 1 & Anisole & $S$ & 1.42 & 2.38 & 2.1 \\
\hline 2 & Linalool & $\mathrm{OM}$ & 6.37 & 7.36 & 6.76 \\
\hline 3 & Geraniol & $\mathrm{OM}$ & 0.51 & 1.56 & 1.46 \\
\hline 4 & alpha Copaene & $S$ & 2.31 & 1.71 & 2.07 \\
\hline 5 & Geranyl acetate & $\mathrm{OM}$ & 0.49 & 0.36 & 1.06 \\
\hline 6 & trans-Carryopyllene & $S$ & 39.03 & 26.1 & 25.01 \\
\hline 7 & Germacrene & $S$ & 10.94 & 12.04 & 10.31 \\
\hline 8 & alpha-Humulene & $S$ & 11.59 & 10.79 & 10.83 \\
\hline 9 & alpha Bergamotene & $S$ & 11.29 & - & - \\
\hline 10 & delta-Cadinene & $S$ & 5.44 & 5.36 & 7.64 \\
\hline 11 & Naphthalene & $S$ & 0.13 & 3.4 & \\
\hline 12 & Carryophylene oxide & $\mathrm{S}^{*}$ & 1.19 & 1.29 & 1.21 \\
\hline 13 & Humulene oxide & $\mathrm{S}^{*}$ & 0.2 & - & 0.65 \\
\hline 14 & Globulol & $\mathrm{OM}$ & 0.93 & 2.29 & 2.42 \\
\hline 15 & alpha Longipinene & $S$ & 0.16 & 6.76 & 6.91 \\
\hline 16 & Torreyol & $S$ & 1.82 & 2.95 & 2.84 \\
\hline 17 & alpha Cadinol & $\mathrm{OM}$ & 2.05 & 3.21 & 3.39 \\
\hline 18 & Farnesol & $\mathrm{OM}$ & 0.69 & 1.78 & 1.98 \\
\hline 19 & Benzyl benzoate & $\mathrm{HOC}$ & 2.98 & 1.75 & 4.14 \\
\hline 20 & Farnesyl acetate & $\mathrm{OM}$ & 0.45 & 0.11 & 0.63 \\
\hline 21 & Eugenol & LOC & - & 1.41 & 0.68 \\
\hline 22 & beta Elemene & $S$ & - & 0.65 & 0.63 \\
\hline 23 & alpha Farnesene & $S$ & - & 6.19 & 6.76 \\
\hline 24 & Cububene & $S$ & - & 0.26 & 0.23 \\
\hline 25 & Nerolidol & $\mathrm{OM}$ & - & 0.28 & 0.28 \\
\hline $\begin{array}{l}\text { S } \\
\text { S* }^{*} \\
\text { OM } \\
\text { LOC } \\
\text { HOC }\end{array}$ & $\begin{array}{l}=\text { sesquiterpen hydrocarb } \\
=\text { oxygenated sesquiterpe } \\
=\text { oxygenated monoterper } \\
=\text { light oxygenated compo } \\
=\text { heavy oxygenated comp }\end{array}$ & & & & \\
\hline
\end{tabular}

Table 4. Compound group of essential oil

\begin{tabular}{|c|c|c|c|}
\hline Compound & Crude oil & $\begin{array}{c}\text { Oil extracted by } \\
\text { chloroform }\end{array}$ & $\begin{array}{c}\text { Oil extracted by } \\
\text { ether }\end{array}$ \\
\hline $\mathrm{S}$ & 84.13 & 76.09 & 75.33 \\
\hline $\mathrm{S}^{*}$ & 1.39 & 1.49 & 1.86 \\
\hline $\mathrm{OM}$ & 11.49 & 16.95 & 17.98 \\
\hline $\mathrm{LOC}$ & 0 & 2.82 & 1.36 \\
\hline $\mathrm{HOC}$ & 2.98 & 4.04 & 4.14 \\
\hline
\end{tabular}

IV.

\section{CONCLUSIONS}

The Cananga odorata oil can be produced by a combination of water-steam distillation and solvent extraction using chloroform and diethylether. The mass transfer of the essential oil of water-steam distillation is about $2.52 \times 10^{-6}$ mole/g.min.mmHg and the pure vapor pressure is about $0.152 \mathrm{mmHg}$. The main compound of the essential oil produced by water-steam are trans-carryopyllene $(39.03 \% \mathrm{w} / \mathrm{w})$, alpha humulene $(11.59 \% \mathrm{w} / \mathrm{w})$, alpha bergamotene $(11.29 \% \mathrm{w} / \mathrm{w})$, and germacrene $(10.94 \%)$. The solvent extraction of the essential oil using chloroform and diethylether can be increase the oxygenated compounds, from $15.86 \%$ increase to 25.3 and $25.34 \%$ for solvent of chloroform and diethyl ether, respectively. On the other hand, the sesquiterpen compound can decrease due to purification using solvent extraction by chloroform and diethyl ether, from $84.13 \%$ decrease to 76.09 and $75.33 \%$, respectively. Therefore the solvent extraction by chloroform and diethylether of the cananga essential oil produced by water-steam distillation can increase the oxygenated compound group. 


\section{Acknowledgment}

The research is funded by Regular Research Program of Faculty of Engineering, Semarang State University - Indonesia.

\section{REFERENCES}

[1]. G. G. Guenther, The essential oil, 2nd ed., New York, USA: D. Van Nostrand Company Inc., 1948.

[2]. M. Kristiawan, V. Sobolik, and K. Allaf, "Isolation of Indonesia Cananga oil using multi-cycle pressure drop process", Journal of Chromatography A, vol. 1192, pp. 306-318, 2008.

[3]. U. Muchjajib, and S. Muchjajib, "Effect of Picking Time on Essential Oil Yield of Ylang-ylang (Cananga odorata)", in ISHS Acta Horticulturae 925: XXVIII International Horticultural Congress on Science and Horticulture for People (IHC2010): A New Look at Medicinal and Aromatic Plants Seminar, 2010.

[4]. W. Wongkaew, and K. Chiangthong "The Influence of Stages of Floral Development on Essential Oil Composition in Cananga odorata (Lam.) Hook.f. \& Thomson var. fruticosa (Craib) J. Sinclair*", The Journal of the Royal Institute of Thailand, vol. 30, no. 2, Apr.-Jun. 2005.

[5]. E. E. Stashenko, W. Torres, J. R. M. Morales, "A study of the compositional variation of the essential oil of ylangylang (Cananga odorata Hook Fil. et Thomson, formagenuina) during flower development," Journal of High Resolution Chromatography, vol. 18, Issue 2, pp. 101-104, February 1995.

[6]. E. Stashenko, J. R. Martinez, C. MacKu, T. Shibamoto, "HRGC and GC-MS analysis of essential oil from colombian ylang-ylang (Cananga odorata Hook fil. et Thomson, forma genuina)", Journal of High Resolution Chromatography, vol. 16, Issue 7, pp. 441-444, July 1993.

[7]. A. F. Lindain, R. A. Reglos, C. C. de Guzman, and Ma. L. O. Cedo, "Tissue Culture and Essential Oil Production From Callus Cultures of Ilang-Ilang [Cananga odorata (Lamk) Hook.f. \& Thomson]”, The Philippine Agricultural Scientist, vol. 91, no. 3, pp. 251-260, September 2008.

[8]. M. Romdhane and C. Tizaoui, "The kinetic modelling of a steam distillation unit for the extraction of aniseed (Pimpinella anisum) essential oil", J Chem Technol Biotechnol, vol. 80, pp. 759-766.

[9]. E. Cassel and R. M. F. Vargas, "Experiments and Modeling of the Cymbopogon winterianus Essential Oil Extraction by Steam Distillation”, J. Mex. Chem. Soc., vol. 50(3), pp. 126-129, 2006.

[10]. A. Mindaryani and S. S. Rahayu, "Essential Oil from Extraction and Steam Distillation of Ocimum Basillicum", in Proceedings of the World Congress on Engineering and Computer Science (WCECS2007), October 24-26, 2007, San Francisco, USA.

[11]. H. Van den Dool and P. D. Kratz, "A generalization of the retention index system including linear temperature programmed gas liquid partition chromatography. J. Chromatogr. 11: 463-71 (1963).

[12]. G. G., Brown, A. S. Foust, and D. Katzs, “Unit Operation”, 14nd edition, New York, USA, John Wiley and Sons Inc., 1950.

[13]. R. E., Treybal, "Mass Transfer Operation”, 3nd edition, Tokyo, Japan, McGraw-Hill International Book Co., 1981. 